Usages du français et pratiques d'enseignement en Europe balkanique, centrale et orientale - Grèce,

Serbie, Bulgarie, Moldavie, Hongrie, Allemagne, Russie - XVIIIe - XXe siècles

\title{
La culture française dans l'enseignement du FLE en Serbie : après la Seconde Guerre mondiale, quoi de neuf?
}

\section{Biljana Stikić}

\section{(2) OpenEdition}

1 Journals

\section{Édition électronique}

URL : https://journals.openedition.org/dhfles/4221

DOI : $10.4000 /$ dhfles.4221

ISSN : 2221-4038

\section{Éditeur}

Société Internationale pour l'Histoire du Français Langue Étrangère ou Seconde

\section{Édition imprimée}

Date de publication : 1 juin 2015

Pagination : 155-170

ISSN : 0992-7654

\section{Référence électronique}

Biljana Stikić, «La culture française dans l'enseignement du FLE en Serbie : après la Seconde Guerre mondiale, quoi de neuf ? ", Documents pour l'histoire du français langue étrangère ou seconde [En ligne], 54 | 2015, mis en ligne le 01 janvier 2018, consulté le 01 avril 2023. URL : http://

journals.openedition.org/dhfles/4221 ; DOI : https://doi.org/10.4000/dhfles.4221

Ce document a été généré automatiquement le 1 avril 2023.

Tous droits réservés 


\title{
La culture française dans l'enseignement du FLE en Serbie : après la Seconde Guerre mondiale, quoi de neuf?
}

\author{
Biljana Stikić
}

\section{Introduction}

« Nous sommes, donc, en tant qu'êtres sociaux,

des classeurs classés par nos classements. »

Pierre Bourdieu, La distinction

1 L'importance de la culture dans l'enseignement des langues étrangères moderne est désignée aujourd'hui par le syntagme terminologique compétence culturelle dont les composantes décrivent les connaissances que les apprenants doivent maitriser. Le Cadre européen (CECRL) dispose de tout un éventail de termes dérivés du mot culturel (comme pluriculturel, multiculturel, interculturel, transculturel, etc.), ce qui témoigne du grand nombre de réflexions sur cet aspect particulier de l'apprentissage des langues. La culture a historiquement fait partie intégrante de l'enseignement des langues comme on peut le voir dans des manuels de conversation destinés à l'usage d'un public extrascolaire. Le présent article aborde justement cette problématique dans le cadre de l'enseignement public du français langue étrangère organisé en Serbie à deux époques politiquement tout à fait différentes. La première est celle de l'entre-deux-guerres, époque où le français était LE1 dans tous les collèges et lycées du Royaume de Yougoslavie, alors que la seconde concerne la première décennie après la Seconde Guerre mondiale, dans le système socialiste de la République Fédérative Populaire de Yougoslavie qui favorisait l'apprentissage du russe. Compte tenu de cette opposition importante, nous avons opté pour une approche contrastive dans le procédé d'analyse de l'importance et des caractéristiques de la culture française présentée dans les programmes d'enseignement et dans les manuels de français. Pour la période de 
l'entre-deux-guerres, des recherches approfondies ont été entreprises auparavant ${ }^{1}$, ce qui nous a aidée à réaliser ces études. En revanche, la seconde partie de l'article peut être classée parmi les travaux originaux puisque la didactique historique du FLE en Serbie ne disposait pas de données sur la période d'après-guerre ${ }^{2}$. Pour ce qui est des procédés d'analyse, il faut d'abord souligner que la notion de culture est prise ici en considération indépendamment de la notion littérature, d'après les rédacteurs de programmes d'alors. Le contenu des programmes et des manuels de français qui constituent notre corpus, a été examiné de deux points de vue: a) celui des composantes culturelles explicitement données sous forme des textes-leçons dont les titres et sujets reflétaient clairement un phénomène culturel ; b) celui des composantes culturelles implicites qui avaient été sporadiquement intégrées par ou dans des textes (puisqu'il y avait des modifications effectuées par des auteurs serbes sur les textes originairement français).

2 Il faut mentionner que l'enseignement institutionnel du français en Serbie a une tradition qui remonte au milieu du xIX siècle. L'importance du français comme matière scolaire changeait selon les circonstances politiques et économiques responsables d'une rivalité constante avec la langue allemande (Polovina 1964; Stikić 2009). Un grand changement se produisit au cours de la Grande Guerre (1915-1916), lorsque quelques milliers d'élèves et d'étudiants serbes, accompagnés de leurs professeurs, quittèrent la Serbie comme réfugiés pour continuer leur formation en France. Cet événement politico-éducatif et interculturel avait influencé quelques générations de jeunes Serbes qui, après leur retour en Serbie libérée, contribuèrent à la propagation de la culture française (Stikić 2012). En 1918 fut créé un pays européen nouveau, le Royaume des Serbes, Croates et Slovènes (nommé un peu plus tard Yougoslavie) qui réunit plusieurs peuples des Balkans, dont certains eurent leur propre destin national sous la souveraineté de la Monarchie austro-hongroise.

\section{Le français dans la Serbie du Royaume de Yougoslavie}

3 La structure de base de l'éducation publique en Yougoslavie, et par la suite en Serbie, était relativement simple : quatre ans de scolarisation obligatoire à l'école primaire, ensuite, à l'âge de 12 ans, le premier cycle de l'enseignement secondaire d'une durée de quatre ans dans un collège ou dans une école à orientation professionnelle (građanske škole). Le deuxième cycle correspondait à une formation quadriennale dans un lycée d'enseignement général ou dans un établissement d'enseignement professionnel (écoles normales primaires, écoles de commerce, écoles d'agriculture, écoles techniques, etc.). L'apprentissage d'une LE1 commençait en première année du premier cycle et finissait en classe terminale des lycées, il durait donc quelque huit ans dans le cas où les élèves recevaient une formation secondaire complète. Le français y était alors la première langue étrangère avec trois heures de cours par semaine, alors que dans les écoles d'enseignement professionnel on n'apprenait, en principe, qu'une seule langue étrangère : l'allemand, le français ou, dans des cas extrêmement rares, le russe, l'italien ou l'anglais (Stikić 2007 : 37-50). 


\subsection{Programmes d'enseignement et manuels de français}

4 Pendant la période qui précède l'entre-deux-guerres, la notion de culture, ou plutôt celle de civilisation, désignait ordinairement un ensemble assez large d'activités qui concernaient les arts, les sciences, l'industrie, la littérature, les mœurs, etc. Le programme d'enseignement du français destiné aux collèges serbes avait été rédigé immédiatement après la Guerre, mais il contenait peu de précisions et avait totalement négligé la question des thèmes à traiter. C'est en 1926 qu'on avait recommandé, lors de la $2^{\mathrm{e}}$ année de l'apprentissage du français, quelques tâches de type culturel et, peutêtre, des indications du début d'une forme élémentaire d'approche interculturelle: «Introduction à la culture spirituelle et matérielle du peuple français, ainsi que leurs principales liaisons avec 'notre peuple' » (Ministarstvo 1920 ; 1923 : 171-173 ; $1927: 183$, 219-220). En 1930, l'enseignement du français avait été culturellement orienté dans la $4^{\mathrm{e}}$ année de l'apprentissage, c'est-à-dire à la fin du premier cycle : Paris et la France, la connaissance de sa culture, de la vie quotidienne et de son histoire (Ministarstvo 1936a : 105; 1936b). Quant au deuxième cycle, la présence de la culture française n'était explicite que dans les programmes de 1931, destinés aux écoles normales primaires, qui recommandaient la lecture et l'analyse d'une œuvre très connue à l'époque : Le tour de la France par deux enfants. Le but en était de faire connaître aux élèves la langue de tous les jours, parlée en France, ainsi que la culture générale ${ }^{3}$ des Français (Ministarstvo 1931: 43-44). Il est important d'indiquer que, du point de vue des rédacteurs des programmes, la culture avait un statut autonome par rapport à la littérature (française) prévue pour être étudiée dans les lycées, comme partie intégrante de l'apprentissage du français.

L'excellente position que le français avait occupée dans l'entre-deux-guerres en Serbie, avait donné naissance à un remarquable développement de l'activité éditoriale. Les publications qui servaient de base pour l'enseignement $\mathrm{du}$ français scolaire appartenaient à un groupe de manuels nommés «livres de lectures françaises » (francuske čitanke). Peu nombreux au début de cette époque, ils se multiplièrent si bien que leur quantité et leur qualité, étaient importantes à la fin des années trente.

\subsection{Composantes culturelles}

6 Les renseignements sur la géographie de la France dans les manuels destinés au premier cycle étaient sporadiquement présents à travers des textes intitulés le plus souvent La France. Dans ces textes, en général sans illustration, on donnait des informations principalement sur la position du pays, les grandes villes, les montagnes, les fleuves et le climat. Cependant, les consignes du programme de 1930 avaient changé cette approche de telle manière que toute une multitude de textes et de données géographiques avaient été introduits en quatrième année. À l'exception des textes à sujets généraux (Un peu de géographie; La France limites; Villes importantes de la France; La France: montagnes, fleuves, rivières; Routes, chemins de fer et canaux de la France; Division administrative de la France, etc.), certains traitaient d'une région ou d'un phénomène géographique particulier. Bien que l'enseignement du français pendant le deuxième cycle ait été consacré à l'étude de textes littéraires, on pouvait donc y trouver occasionnellement des renseignements sur la France et son rôle dans le monde. Il semble que l'histoire de France, très riche en événements, n'avait pas beaucoup inspiré les auteurs de manuels. Il ne s'agissait pas d'absence de textes historiques, mais d'une 
certaine approche unilatérale qui ne favorisait qu'une époque, tout d'abord celle des Gaulois. D'autre part, des textes sur la France médiévale et celle de la Révolution française apparaissaient sporadiquement, mais étaient beaucoup moins nombreux que les textes qui, d'une manière plus ou moins explicite, glorifiaient des rois de France. Si les événements les plus importants de l'histoire de France ne représentaient pas les sujets principaux des leçons, ils apparaissaient cependant comme une sorte de décor dans les textes sur la vie de personnages historiques. C'étaient, en principe, des textes brefs décrivant les mérites de Charlemagne, le courage de Roland et de Jeanne d'Arc, ainsi que de nombreux textes sur la vie de Napoléon I ${ }^{\mathrm{er}}$, complétés d'illustrations de qualité. C'est probablement la première fois que certains auteurs de manuels destinés aux élèves serbes ont introduit des textes sur la mentalité des Français, sans éviter parfois de mentionner l'esprit régional, à travers des anecdotes choisies. Ce que les auteurs serbes d'année en année s'empruntaient les uns aux autres, c'était de mettre en avant le trait principal du peuple français : le goût pour la conversation. Pour présenter une telle image aux élèves, des auteurs se servaient le plus souvent de textes de Madame de Staël (Les Français et la conversation) ou d'Hippolyte Taine (Le Français causeur).

7 Les textes décrivant les mœurs et la vie quotidienne n'étaient pas particulièrement nombreux. Dans les cas où des auteurs s'étaient tout de même décidés à donner quelques informations, il s'agissait presque toujours de descriptions de la vie scolaire française, de la fête nationale et de fêtes religieuses, de voyages et d'achats.

8 Étant donné que la capitale de la France avait été présentée par les programmes comme un élément principal de la culture française, il n'est pas étonnant que les manuels en offrent une multitude de textes abondamment illustrés. À l'exception de nombreux textes consacrés à la ville de Paris dans son ensemble, la capitale de la France avait été aussi présentée sous ses divers aspects, notamment du point de vue de ses monuments historiques et culturels, alors que certaines leçons-textes avaient été rédigées sous forme de brefs guides de Paris.

Il faut aussi mentionner la particularité que représentait l'absence de sujets artistiques dans les programmes d'enseignement. Cette lacune avait été comblée dans un manuel publié à la fin de cette période, qui abondait en reproductions de tableaux de peintres français empruntés au célèbre ouvrage d'époque Collection des maitres par Braun et Cie (Stikić 2007 : 236-245). La question de savoir comment ces contenus artistiques étaient exploités pendant les cours de français restera probablement sans réponse comme, d'ailleurs, toute autre question concernant des actes et situations dont il n'y a plus d'acteurs ni de témoignages.

\section{Le français dans la Serbie socialiste}

10 La fin de la Seconde Guerre mondiale avait laissé le territoire de la Serbie dévasté, avec un grand nombre de victimes, de blessés et de malades. Ceux qui avaient réussi à survivre débutaient une vie nouvelle dans la liberté. Mais, bien que la Guerre soit terminée, de nombreuses luttes avaient déjà commencé : contre la faim et la pauvreté, de grandes migrations de population dans des régions plus favorables à la vie, la fondation des coopératives agricoles, des travaux publics et, surtout, les « règlements des comptes» continuels avec des ennemis du nouveau système politique et des partisans du régime précédent. La Yougoslavie socialiste avait « hérité » de presque 
tout le territoire de Royaume, mais sa division administrative comprenait six républiques populaires dont l'une était la Serbie. Alliée de l'Union des Républiques Socialistes Soviétiques entre 1945-1948, la Yougoslavie s'était pourtant développée d'une manière assez autonome comme un des pays les plus stables de l'Europe de l'Est. Des tentatives d'influence de l'URSS sur le pouvoir politique yougoslave avaient produit en 1948, un conflit entre les deux pays, connu sous le nom d'Informbiro. Les conséquences en étaient assez graves, et ont conditionné l'orientation de la Yougoslavie vers l'Occident (Pantelić 2011). À partir de 1948, les relations entre la Yougoslavie et la France deviennent plus intenses. Excepté le début de la coopération à plusieurs niveaux parmi lesquels le domaine de la science et de la culture, la France et la Yougoslavie avaient établi des relations économiques (Petrović 2006 : 30-31).

11 Pendant cette première décennie d'après-guerre, les autorités de l'Instruction publique de la République populaire de Serbie firent rédiger plusieurs programmes destinés à l'enseignement primaire et secondaire, ainsi que leurs corrections et compléments. Cette courte période peut être divisée en deux parties importantes. La première est celle de la domination de la langue russe dans un système éducatif dont la structure de base était pareille à celle de la Yougoslavie de l'entre-deux-guerres. La seconde partie commence en 1950, avec l'instauration de l'école primaire de huit ans embrassant ainsi une sorte d'enseignement primaire et celui donné au collège, suivi par quatre ans de lycée ou d'un deuxième cycle d'enseignement professionnel. Puisque La formation selon le système d'éducation précédent n'ayant pas encore été supprimée, il y a coexistence de deux systèmes éducatifs dans cette période de transition.

\subsection{La culture « programmée »}

Le premier programme d'enseignement en vigueur durant l'année scolaire 1945-1946, a mis en relief deux buts importants dont le second portait sur la culture: "Faire connaitre aux élèves le peuple qui parle cette langue étrangère, les pays où l'on l'utilise ainsi que leur culture spirituelle et matérielle» (Ministarstvo 1946a: 3). Bien que la langue russe soit alors présente pendant huit ans, et le français ou l'anglais pendant quatre ans au lycée, ces exigences du type culturel concernaient toute LE (Ministarstvo 1946b : 3,4 ; 1948a : 3). Le programme de français avait introduit des composantes culturelles dans une optique interculturelle à orientation patriotique et politique. À l'exception de quelques événements et grandes dates de la République française, on recommandait de traiter des thèmes comme le soutien à la nouvelle idéologie yougoslave : enfants pionniers du socialisme, jeunesse yougoslave et ses associations, libération de Belgrade en 1944, lutte des partisans, État de Yougoslavie, etc. On indiquait des textes de Molière, de La Fontaine, de Michelet et de Daudet sur l'histoire et la vie quotidienne de France. En dernière année de l'apprentissage du français, le programme s'oriente vers la «culture française " à travers des textes d'écrivains français sur la lutte du peuple français pour sa liberté (Voltaire, Diderot, Rousseau, Hugo, Zola, Balzac) ainsi que des textes rédigés pendant la Seconde Guerre mondiale : Vildrac, Aragon, Eluard, Durtain et Cricelt (Ministarstvo 1946a : 13-15; 1948a : 5-6). Pour l'année scolaire 1948-1949, le français, l'anglais et l'allemand furent introduits en quatrième année du collège, ce qui signifiait cinq ans d'apprentissage d'une LE autre que le russe. C'est à partir de la deuxième année de cet enseignement qu'on recommandait l'introduction de textes sur la géographie et l'histoire de France, mais, en même temps, celle de textes sur «notre réalité sociale », ce qui devait être complété 
pendant la troisième année à travers le lexique de la vie politique yougoslave. La culture y était marginale dans la mesure où l'on n'exigeait que quelques textes sur de célèbres personnages français. L'apprentissage du français pendant les quatrième et cinquième années avait été fondé sur l'étude de textes relevant du domaine social et politique yougoslave, notamment celui concernant le développement du socialisme, la lutte pour la paix et la démocratie, la solidarité des «peuples travailleurs du monde entier ", ainsi que l'étude des textes littéraires des $\mathrm{xIX}^{\mathrm{e}}$ et $\mathrm{xx}^{\mathrm{e}}$ siècles décrivant avec réalisme la société française et la lutte du peuple français pendant la Seconde Guerre mondiale (Ministarstvo 1948b : 3, 28-35).

Les programmes d'enseignement publiés en 1950 avaient placé sur un pied d'égalité toutes les LE, si bien qu'on choisissait celle qu'on apprenait dès la première année du collège, alors qu'une LE2 était prévue à partir de la quatrième année (Ministarstvo 1950 : 3-4). Pour ce qui est de la première année, on recommandait l'apprentissage du vocabulaire concernant l'environnement des élèves, la vie familiale et celle des pionniers, des textes décrivant la vie quotidienne, des poésies et des chansonnettes. C'était presque la même tâche dans la deuxième année, alors que l'apprentissage du français en troisième année portait sur les villes et les villages, les travaux publics, les usines, la géographie de la France et de "notre» pays. Des changements de programmes étaient plus évidents dans la dernière année. Excepté des textes reflétant l'humanisme et le patriotisme du peuple français, les grandes dates de l'histoire de France liées à celles de l'histoire yougoslave et du rôle de la jeunesse dans le socialisme, étaient recommandés des textes relevant du domaine des sciences, de la France quotidienne avec le théatre, les concerts, les expositions et les films (Ministarstvo $1952: 12-17)$.

\subsection{Composantes culturelles dans les manuels}

Un petit nombre de manuels de français à l'usage des élèves avaient été publiés pendant la première décennie d'après-guerre, les premières éditions datant de 1947. Le second "paquet " éditorial avait été lancé en 1950, non seulement en raison des changements politiques, mais aussi en raison de l'instauration d'un nouveau système d'éducation. Dans ces manuels, il s'agissait d'une approche assez moderne, avec, souvent, de nombreuses illustrations, des exercices avec variations de leurs types, et aussi des unités particulières d'explications grammaticales et lexicales.

Le premier fait évident était une approche interculturelle avant la lettre. La particularité de cette approche réside dans les procédés de création sporadique de triangles interculturels d'origine idéologique. Concrètement apparaissaient dans ces manuels, et notamment dans les manuels publiés avant 1951-1952, des éléments de la réalité socialiste yougoslave, des réalités politico-culturelles soviétiques et on assistait donc à une marginalisation de la culture française au profit de grandes dates et événements de France idéologiquement acceptables. L'analyse des manuels destinés aux débutants montre que cet étrange triangle d'endoctrinement servait de principe pour le choix des textes et de leurs adaptations. On peut constater que presque chaque donnée de type culturel sur la société française moderne était idéologiquement colorée ou modifiée de manière à ce qu'elle soit compatible avec des principes du socialisme yougoslave. En voici un exemple : 
Leçon 17 : Quelques produits français

La France produit des céréales, surtout du blé. [...] La terre française est riche et belle, mais les principaux moyens de production appartiennent à un petit nombre de privilégiés - "les deux cents familles»; ce fait empêche le progrès en France. Le peuple travailleur de France lutte pour rendre à tous les richesses de la terre française. [...]. (Košanin-Anaf 1948 : 127)

16 Il faut aussi mentionner le fait que des auteurs introduisaient sporadiquement des textes sous forme de lettres que des élèves serbes et français «échangeaient » entre eux, et par lesquelles ils renseignaient leurs parents et amis de France sur leurs vacances passées en Yougoslavie, le plus souvent dans des camps de pionniers (Košanin-Anaf 1948: 165；1953: 194; Vujanac 1953: 33, 92). Quant au triangle idéologique mentionné, qui avait marginalisé la culture française au profit d'éléments soviétiques, il s'agissait des composantes explicites, comme des textes sur des personnalités de l'histoire russe et soviétique ou, le plus souvent, des composantes implicites présentes sous forme de noms d'écrivains soviétiques et de leurs œuvres, noms de villes et de rue, prénoms de participants de dialogues, etc. Cependant, certains auteurs de manuels de français publiés immédiatement après la guerre n'avaient pas tenu compte d'une telle approche strictement idéologique, si bien que des composantes culturelles françaises étaient plus fréquentes et tout à fait explicites: des villes françaises (Lyon, Marseille, Bordeaux), Sur les quais de la Seine; Aux alentours de St. Germain des Près; Voyages dans Paris; Visite au XI $\mathrm{XI}^{e}$ arrondissement ; Cimetière du Père Lachaise, etc. (Cheymol-Vukasović, 1947) 4 .

Pour ce qui est des niveaux supérieurs de l'apprentissage du français, c'étaient des textes (morceaux choisis) littéraires qui constituaient la base de l'enseignement du français. Des composantes culturelles y apparaissaient occasionnellement et d'une manière implicite, sous forme de données sporadiques, comme une sorte de « scénographie » de textes en question, qui n'avaient pas encore été libérés d'éléments idéologiques (Marodić et Dimitrijević $1950 ; 1952 ; 1953)$. Juste à la fin de cette période, avait pourtant été publié un manuel qui annonçait une approche plus favorable à la présence de la culture française. Abondamment illustré, ce manuel contenait des textes à sujets différents, depuis la géographie de la France, à travers des descriptions de la vie quotidienne de Paris, jusqu'à la préparation des élèves serbes pour établir la correspondance avec des amis français. Ces pas de déblocage culturel où, à partir de la première leçon qui traitait de la conversation sur un séjour en France, l'on parle de la France avec ravissement, contrastent avec les pratiques d'enseignement jusqu'ici mentionnées :

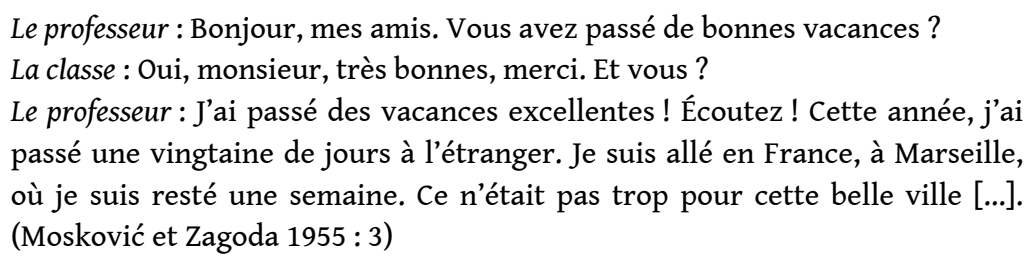

Naturellement, il ne s'agissait pas de procédés indépendants du programme, mais d'un autre aspect de l'interprétation de ses consignes par rapport aux auteurs de manuels publiés quelques années auparavant. Cependant, la preuve que la politique représentait encore " un fort cadre d'orientation didactique " était celle relative à l'Informbiro. Ce grave conflit avec l'URSS avait obligé les auteurs des manuels de français à faire des 
corrections dans le contenu des manuels, qui consistaient à effacer et remplacer la plupart des « éléments » soviétiques.

\section{Conclusion}

19 Les autorités éducatives dans la Serbie de l'entre-deux-guerres et-d'après-guerre avaient introduit la culture française comme l'un des objets de l'enseignement public $\mathrm{du}$ français, montrant ainsi qu'elles étaient conscientes de son importance pour la connaissance et la maîtrise de cette langue étrangère. L'entre-deux-guerres avait déjà connu l'interculturalité fortement ouverte vers la culture française au moyen de textes décrivant la géographie de la France, des événements et des personnages historiques, de la vie quotidienne et, surtout, de la capitale de la France. Étant données les circonstances politiques du pays, on peut constater que la composante idéologique jouait un rôle minimal, à savoir que les auteurs de manuels ne s'occupaient pas particulièrement de textes qui glorifiaient des périodes monarchiques. D'autre part, la première décennie d'après-guerre avait développé d'une manière remarquable l'approche interculturelle, mais de façon tout à fait opposée à ce qui était le cas dans l'entre-deux-guerres. Pour ce qui est du cycle inférieur de l'apprentissage du français, des textes de manuels avaient été complètement orientés pour une valorisation explicite et implicite du nouveau système politique du socialisme. En introduisant des éléments à orientation russe et soviétique, programmes et manuels avaient marginalisé la culture française dont des composantes émergeaient pendant le cycle supérieur lorsqu'on avait étudié la littérature française. Cependant, le contenu d'un manuel de français publié à la fin de cette période témoigne d'un lent déblocage idéologique, ce qui avait rendu possible une tolérance culturelle plus grande.

BIBLIOGRAPHIE

\section{Sources primaires}

\section{Documents du ministère de l'Instruction publique de Serbie et de Yougoslavie}

MINISTARSTVO prosvete Kraljevine Srba, Hrvata i Slovenaca :

(1920). Srednješkolski zbornik II [Programmes, règlements et recommandations destinés à l'enseignement secondaire II]. Beograd.

(1923). Srednješkolski zbornik III [Programmes, règlements et recommandations destinés à l'enseignement secondaire III]. Beograd.

(1925). Srednješkolski zbornik IV [Programmes, règlements et recommandations destiné à

l'enseignement secondaire IV]. Beograd. 
(1927). Srednješkolski zbornik $V$ [Programmes, règlements et recommandations destinés à l'enseignement secondaire V]. Beograd.

MINISTARSTVo prosvete Kaljevine Jugoslavije :

(1931). Privremeni nastavni plan za učiteljske škole u Kraljevini Jugoslaviji [Plan d'enseignement provisoire destiné aux écoles normales primaires dans le Royaume de Yougoslavie]. Beograd.

(1936a). Programi i metodska uputstva za rad u srednjim školama [Programmes d'enseignement et consignes méthodologiques destinés aux établissements d'enseignement secondaire]. Beograd.

(1936b). Nastavni plan i program za I, II, III i IV razred građanskih škola u Kraljevini Jugoslaviji [Plan et programme d'enseignement dans les classes Ire - IVe des écoles bourgeoises]. Beograd.

MINISTARSTVo prosvete Narodne Republike Srbije :

(1946a). Nastavni plan i program za gimnazije : za školsku 1945/46 godinu : ruski, francuski i engleski jezik (latinski jezik) [Plans et programmes d'enseignement destinés aux lycées ; l'année scolaire 1945-1946 : le russe, le français et l'anglais (le latin)]. Beograd : Prosveta.

(1946b). Nastavni plan i program za gimnazije : dopune i izmene plana i programa za školsku 1946/47 godinu [Plans et programmes d'enseignement destinés aux lycées : leurs suppléments et corrections valables dans l'année scolaire 1946-1947]. Beograd : Prosveta.

(1948a). Nastavni plan i program za gimnazije i učiteljske škole za školsku 1947/8: ruski jezik, francuski jezik i engleski jezik) [Plans et programmes d'enseignement destinés aux lycées et aux écoles normales primaires; 1947-1948 : le russe, le français et l'anglais]. Beograd : Prosveta.

(1948b). Nastavni plan i program za gimnazije za školsku 1948/49 godinu sa metodskim uputstvima: francuski, engleski i nemački jezik, latinski jezik) [Plans et programmes d'enseignement avec consignes méthodologiques valables dans l'année scolaire 1948-1949 : le français, l'anglais et l'allemand, le latin)]. Beograd : Znanje.

(1950). Izmene i dopune u programima za sve predmete od II do VIII razreda gimnazije za školsku 1950/51 godinu) [Corrections et suppléments des programmes d'enseignement de toutes les matières à partir des classes IIe jusqu'aux classes VIIIe des lycées ; 1950-1951]. Beograd : Znanje.

SAVET za prosvetu, nauku i kulturu NR Srbije :

(1951). Nastavni plan i program za V, VI i VII razred osmogodišnje škole i I, II i III razred gimnazije [Plans et programmes d'enseignement dans les classes $\mathrm{V}^{\mathrm{e}}, \mathrm{VI}^{\mathrm{e}}$ et $\mathrm{VII}^{\mathrm{e}}$ de l'école primaire, et dans les classes $\mathrm{I}^{\mathrm{re}}, \mathrm{II}^{\mathrm{e}}$ et III ${ }^{\mathrm{e}}$ des lycées]. Beograd : Znanje.

(1952). Nastavni plan i program za V, VI, VII i VIII razred osmogodišnje škole i I, II, III i IV razred gimnazije [Plans et programmes d'enseignement dans les classes $\mathrm{V}^{\mathrm{e}}, \mathrm{VI}^{\mathrm{e}}, \mathrm{VII}^{\mathrm{e}}$ et $\mathrm{VIII} \mathrm{e}^{\mathrm{e}}$ de l'école primaire, et dans les classes $\mathrm{I}^{\mathrm{re}}, \mathrm{II}^{\mathrm{e}}, \mathrm{III}^{\mathrm{e}}$ et $\mathrm{IV}^{\mathrm{e}}$ des lycées]. Beograd : Znanje.

\section{Manuels de français publiés en Serbie (1945-1955)}

CHEYMOL-VUKASOVIĆ, M. (1947). Udžbenik francuskog jezika za VI razred gimnazije [Manuel de français destiné à l'usage des lycéens, classe 6e]. Beograd : Prosveta.

GRDENIĆ, D. MOSKOVIĆ, V. (1952). Francuska čitanka za V razred gimnazije [Manuel de français destiné à l'usage des lycéens, classe $\left.5^{\mathrm{e}}\right]$. Beograd : Znanje.

KOŠANIN-ANAF, S. (1947). Udžbenik francuskog jezika za V razred gimnazije [Manuel de français destiné à l'usage des lycéens, classe $5^{\mathrm{e}}$ ]. Beograd : Prosveta. 
KOŠANIN-ANAF, S. (1948). Francuska čitanka za V razred gimnazije [Manuel de français destiné à l'usage des lycéens, classe $5^{\mathrm{e}}$. Deuxième édition]. Beograd : Preduzeće za udžbenike i učila NR Srbije, 2. izdanje.

KOŠANIN-ANAF, S. (1951). Udžbenik francuskog jezika za IV razred gimnazije [Manuel de français destiné à l'usage des lycéens, classe $\left.4^{\mathrm{e}}\right]$. Beograd : Znanje.

KOŠANIN-ANAF, S. (1953). Udžbenik francuskog jezika za V razred gimnazije (I početni tečaj za više razrede). 2. prerađeno izdanje [Manuel de français destiné à l'usage des lycéens, classe $5^{\mathrm{e}}$. Cours pour débutants - classes supérieures. Deuxième édition corrigée]. Beograd : Znanje.

MARODIĆ, D. DIMITRIJEVIĆ, R. (1950). Francuska čitanka za VII $i$ VIII razred gimnazije [Manuel de français destiné à l'usage des lycéens, classes $7^{\mathrm{e}}$ et $8^{\mathrm{e}}$ ]. Beograd : Znanje.

MARODIĆ, D. DIMITRIJEVIĆ, R. (1952). Francuska čitanka za VII $i$ VIII razred gimnazije [Manuel de français destiné à l'usage des lycéens, classes $7^{\mathrm{e}}$ et $8^{\mathrm{e}}$. Deuxième édition]. Beograd : Znanje. II izdanje.

MARODIĆ, D. DIMITRIJEVIĆ, R. (1953). Francuska čitanka za VII $i$ VIII razred gimnazije [Manuel de français destiné à l'usage des lycéens, classes $7^{\mathrm{e}}$ et $8^{\mathrm{e}}$. Troisième édition]. Beograd : Znanje. III izdanje.

MOSKOVIĆ, V. ET ZAGODA, Z. (1951). Udžbenik francuskog jezika za VI razred gimnazije [Manuel de français destiné à l'usage des lycéens, classes $7^{\mathrm{e}}$ et $8^{\mathrm{e}}$. Troisième édition]. Beograd : Znanje.

MOSKOVIĆ, V. ET ZAGODA, z. (1955). Udžbenik francuskog jezika za V razred gimnazije [Manuel de français destiné à l'usage des lycéens, classe $5^{\mathrm{e}} \mathrm{]}$. Beograd : Nolit.

VLADIMIROVIĆ-VUJANAC, R. (1953). Udžbenik francuskog jezika za VI razred osmogodišnje škole i II razred gimnazije [Manuel de français destiné à l'usage aux écoles primaires, classe $6^{\mathrm{e}}$, et dans les lycées, classe $\left.2^{\mathrm{e}}\right]$. Beograd : Znanje.

\section{Sources secondaires}

PANTELIĆ, IVana (2011). Partizanke kao građanke: društvena emancipacija partizanki u Srbiji, 1945-1953 [Les femmes partisans en tant que citoyennes : émancipation sociale des femmes partisans en Serbie 1945-1953]. Beogra Evoluta, Institut za savremenu istoriju.

<http://www.danas.rs/danasrs/feljton/informbiro_prekretnica_za_emancipaciju_zena.24.html? news_id=215836> (20 juillet 2014).

PETROVIĆ, D. (2006). Kulturna politika francusko-jugoslovenskih odnosa 1949-1959 [La politique culturelle des relations franco-yougoslaves 1949-1959]. Beograd : Institut za političke studije.

POLOVINA, Pera (1964). Udžbenici francuskog jezika kod Srba do 1914. godine [Les manuels de français chez les Serbes jusqu'en 1914]. Beograd : Društvo za strane jezike i književnosti.

STIKIĆ, Biljana (2007). Nastava francuskog jezika u Srbiji 1918-1941 [L'enseignement de la langue française en Serbie 1918-1941]. Novi Sad : Filozofski fakultet. (Première version de cette thèse de doctorat).

STIKIĆ, Biljana (2009). « Počeci srednjoškolske nastave francuskog jezika u Srbiji » [L'introduction du français dans l'enseignement secondaire de Serbie]. Naučni skup Jezik, književnost, identitet / Conference Language, Literature, Identity, Departman za anglistiku, 24-25 april 2009. Filozofski fakultet Univerziteta u Nišu, 237-248.

STIKIĆ, Biljana (2012). Usvajanje stranog jezika u specifičnom kontekstu: francuski jezik i Srbi u Prvom svetskom ratu [L'apprentissage de langue étrangère dans un contexte particulier : le français et les Serbes au cours de la Grande Guerre]. Novi Sad : Akademska knjiga. 


\section{NOTES}

1. Il s'agit des recherches entreprises dans le cadre de notre thèse de doctorat intitulée Nastava francuskog jezika u Srbiji 1918-1941 [L'Enseignement du français en Serbie 1918-1941] soutenue en 2008 à l'Université de Novi Sad.

2. En fait, le premier article dans lequel nous analysions l'enseignement du français d'aprèsguerre a été récemment publié : Stikić, B. (2014). « Političko-ideološki aspekat posleratne nastave francuskog jezika u Srbiji 1945-1953» [L'aspect politico-idéologique de l'enseignement du français en Serbie d'après-guerre 1945-1953]. Metodički vidici, 5, 97-113.

3. La formulation originale, donnée en langue serbe, "opšta kultura francuskog naroda » [la culture générale des Français] est ambiguë. Il s'agissait probablement de la vie quotidienne de la majorité de la population française.

4. Dans l'entre-deux-guerres, Marcèle Cheymol-Vukasović était lectrice de français à la Faculté des Lettres de Belgrade. Elle avait donné des cours de français à Radio Belgrade et pris part à l'organisation des stages d'été de l'Institut français de Belgrade.

\section{RÉSUMÉS}

L'analyse des matériaux didactiques publiés pour l'enseignement du français en Serbie dans l'entre-deux-guerres et pendant la première décennie d'après-guerre montre que les caractéristiques du système politique de ces deux périodes déterminèrent la place et la présence de la culture dans l'enseignement public du français. Le français est la LE1 dans l'entre-deuxguerres, et la culture y est abordée au cours d'une année de l'apprentissage, avec la thématique de Paris, l'histoire et la géographie de la France, ainsi que par certains aspects de la vie quotidienne. Cependant, des composantes culturelles implicites se retrouvaient dans presque tous les manuels de français. Dans l'après-guerre, le français subissant la domination du russe, les programmes et, par conséquent, les manuels, « marginalisèrent » la culture française en créant un étrange triangle de composantes interculturelles idéologiques qui favorisait la réalité socialiste yougoslave à la lumière de l'histoire de France révolutionnaire, communiste et antifasciste, avec des textes à orientation soviétique.

The analysis of high-school curricula and the course books, which had been published in the inter-war and the post-war Serbia, shows that the ideological and political characteristics of both periods had determined the presence of culture in the French language learning. It was the FL1 in the inter-war period in which cultural task had concerned Paris, the history and the geography of France, and some aspects of everyday life. However, the implicit cultural components were sporadically in almost all French textbooks. As for the French learning in postwar Serbia, which were dominated by Russian, the high-school curricula and the French course books had almost marginalized French culture, and created a strange triangle of ideological intercultural components, which promoted socialist reality of Yugoslavia linked to the history and events of revolutionary, communist and anti-fascist France, supported sporadically by the implantation of elements of Soviet guidance. 
INDEX

Mots-clés : Culture, français langue étrangère, Serbie, Yougoslavie (1918-1955)

Keywords : Culture, French language learning, Serbia, Yougoslavia (1918-1955)

\section{AUTEUR}

\section{BILJANA STIKIĆ}

Université de Novi Sad - Serbie 